\title{
TABLE OF DECISIONS
}

\section{TABLE OF DECISIONS OF THE COURT OF THE COMMISSIONERS OF THE ALABAMA CLAIMS}

Barling v United States

Brott v United States

Buck and Spofford v United States

13-138

Butman v United States

13-137

Cassidy v United States

13-150, 14-130, 14-153

Catch v United States

13-137

Chadwick v United States

Eldridge v United States

Fisler v United States

Gannett v United States

Geoghegan v United States

Gordon v United States

Haskins v United States

Haven and Williams v United States

Homer and Sprague v United States

Hubbell v United States

Hutchinson v United States

Hyneman v United States

Ignacio v United States

Levois v United States

Lord and Munn v United States

MacLeane v United States

Montgomery v United States

Munn v United States

Osborn v United States

Pacific Mills v United States

13-133, 13-144

Phillips v United States

Pike v United States

Rhind v United States

Rich and Paine v United States

Robeson, Secretary of the Navy v United States

Rodocanachi v United States

Schrieber and Meyer v United States

Schreiber v United States

Sherman, Hubbell and Gillian v United States

Ships James Maury, General Pike, Milo and Nile, Re

Smith v United States

Stevens v United States

Swift v United States

Taylor v United States

Warren v United States

Williams v United States 